\title{
An initial investigation on the potential applicability of Acoustic Emission to rail track fault detection
}

\author{
Kristoffer Bruzelius, D. Mba \\ ${ }^{1}$ School of Engineering, Cranfield University, Cranfield, Bedfordshire, UK. MK43 0AL
}

\begin{abstract}
In light of recent accidents in the rail industry, the assessment of the mechanical integrity of rail-track is of vital importance. This encompasses the integrity of the track due to rolling contact fatigue and surface wear. Whilst numerous techniques are employed for crack detection, several defects have clearly been missed. In Europe more than 100 rails are broken each year and rail maintenance costs within the European Union is estimated at 300-million Euros annually [1]. The derailment of a train at Hatfield in October 2000 is a tragic example of a fractured rail going undetected.
\end{abstract}

This paper presents an experimental study on the applicability of Acoustic Emissions for rail-track defect diagnosis. An experimental test-rig was employed for this programme. This allowed for a surface defect to be seeded onto the test-rig. The investigation presented is part of an on-going attempt to develop the non-destructive technique of Acoustic Emissions (AE) for assessing the surface integrity of rail-track. The AE technique is not new but the application in this particular instance is unique. It is concluded that the AE technique offers a complementary tool for rail track defect detection.

Keywords: Acoustic Emission, condition monitoring, rail track diagnosis. 


\section{RAIL TRACK DEFECTS}

The phenomenon of wear and cracks in rail track due to rolling contact fatigue is not fully understood. Different defects types appear in rail tracks and there are various mechanisms responsible for this such as corrosion, rolling contact fatigue, creep and wear, with rolling contact fatigue and wear constituting the two most prominent. The rolling contact fatigue of rails manifest as headchecks, torgue lipping, squats, false flange damage, wheel burns and spalling [2]. The stages of initiation and growth are widely detailed.

It has been showed [2] that ultrasound can be used to detect cracks in rails. Ultrasonic inspection of rails requires use of several probes in order to increase the probability of detecting cracks. For reasons of geometry ultrasound is not suitable for detecting defects in the gauge corner [2,3]. Krull et al [3] showed that the eddy current technique was suitable to detection of fine cracks on the surface of the rail. Whilst techniques such as ultrasound and eddy current testing can be employed for crack detection on rail-tracks, several defects have clearly been missed.

\section{ACOUSTIC EMISSION IN RAIL TRACK}

Measurement of high frequency Acoustic Emissions (AE) has become a viable technique in the condition monitoring of many types of rotating machinery [4-9]. On real operational machinery, it is often only practical to take AE measurements from non-rotating members, at or on the bearing housing. Consequently, AE signals 
originating from any component other than the bearing will incur significant attenuation to an AE receiving sensor attached on the bearing housing. However, recent attempts [4] at locating the AE receiving sensor on rotating parts have been encouraging.

Acoustic emission is a naturally occurring phenomenon within materials and is defined as the resulting transient elastic wave generated when strain energy is released suddenly within or on the surface of a material. This is due to microstructure changes such as, dislocations, crack generation and propagation, friction phenomena within a crack, plastic deformation, fracture of brittle inclusions, fibre breakage, etc. These changes can be generated internally or externally and cover a broad frequency range between $20 \mathrm{kHz}$ to $1 \mathrm{MHz}$. An added advantage of using the AE technique is that it is independent of rotational velocities.

Acoustic emissions as described in this paper refer to elastic surface waves generated entirely by the rubbing/frictional of mating components. The formation, deformation, and fracture of surface irregularities or asperities, which is associated with friction of metals [10], will result in the generation of AE. Publications on the application of AE to rail-track defect detection are non-existent at present and this paper provides a fundamental assessment of its application to rail-track defect detection. In light of the recent, and past, accidents in the rail industry, the assessment of the mechanical integrity of rail track is of vital importance. AE is widely used for crack detection in static structures and Bassim et al [11] showed that crack initiation and progression in rail steel specimens exposed to bending can be detected using the AE technique. 
Studies in the application of AE to tribology are relevant to the current investigation on rubbing faces of the wheel and track. Researchers [12,13] have investigated wear between loaded metal surfaces in relative motion, with or without lubrication, and concluded that $\mathrm{AE}$ can be used to determine the onset and the rate of wear between components. The source of AE activity was attributed to the breaking of surface asperities and the formation and destruction of the friction contact. Sarychev [12] observed that the strength of AE depended on; sliding velocity, friction coefficient of mating surfaces, contact pressure and the height of surface roughness, while Lingard [13] noted that $\mathrm{AE}$ was attributed to frictional forces rather than wear. It may be concluded that the process of wear between contact faces of the wheel and rail-track, and propagation of cracks within the track, will generate AE activity.

\section{TEST RIG}

A schematic diagram of the test-rig is illustrated in figure 1 and shown in figure 2 . The test-rig consisted of two wheels, a rail track wheel and a rail wheel, both scaled down replicas of standard rail/wheel profiles (ratio 3:1). The material employed was mild carbon steel and the surface finish of the wheel and rail was approximately $3 \mu \mathrm{m}$. No surface hardening was employed to allow for accelerated wear, particularly as the initial thrust of this investigation was to ascertain the applicability of AE to surface defect detection. A three-phase electrical motor $(1 \mathrm{~kW})$ with a variable speed mechanical gearbox was employed to drive the test-rig. A belt from the gearbox was connected to a driving rubber wheel (part 9 of figure 1) onto which the rail-track wheel rested. The rail track wheel was rotated solely by frictional contact between the rubber wheel and the 
rail-track wheel. The rail track wheel in turn rotated the rail wheel also by frictional contact. A simple hydraulic mechanism that permitted loading between the rail wheel and track was employed. This was a Parker HC 20T cylinder that provided up to 3000 N.

The main reason for designing the rail and track wheels at $90^{\circ}$ to each other was to simulate the best condition conducive for the generation of surface defects, particularly as wear is more prevalent on curved tracks [1]. However, at the time of designing the test-rig due consideration was not given to the effect of sliding between the rail wheel/track interface on audible noise generation. In addition, during experimental simulations that required loading between the wheel and the rail further limitations of the test-rig became apparent. As the speed of rotation and load on the rail wheel was increased to $460 \mathrm{rpm}(25 \mathrm{~km} / \mathrm{hr})$ and $1800 \mathrm{~N}$ respectively, the noise levels reached values in excess of $95 \mathrm{~dB}$. At these test conditions the loss of signal transmission between the AE receiving sensor and the acquisition system was experienced. This was attributed to the high amplitude levels of the low frequency carrier (modulating the high frequency AE signature) thereby saturating the band-pass filter on the pre-amplifier (see section on data acquisition system and discussion). As a consequence of the above the maximum load and speed tested were $1800 \mathrm{~N}$ at $200 \mathrm{rpm}(10.5 \mathrm{~km} / \mathrm{hr})$. Whilst this was a clear limitation, it was not thought detrimental to establishing fundamentally if AE could be applied to rail-track diagnosis. Design alterations are currently in process to allow for test simulations to be achieved at speeds of up to $50 \mathrm{Km} / \mathrm{hr}$. This is being accomplished by changing the orientation of the rail track wheel such that both wheels, rail and track, are vertical. Furthermore, alternative methods of transferring the AE signature from the 
receiving sensor to the acquisition system are currently being explored, as are investigations on limitations of current AE sensors.

$$
1
$$

2

3

4

5

6

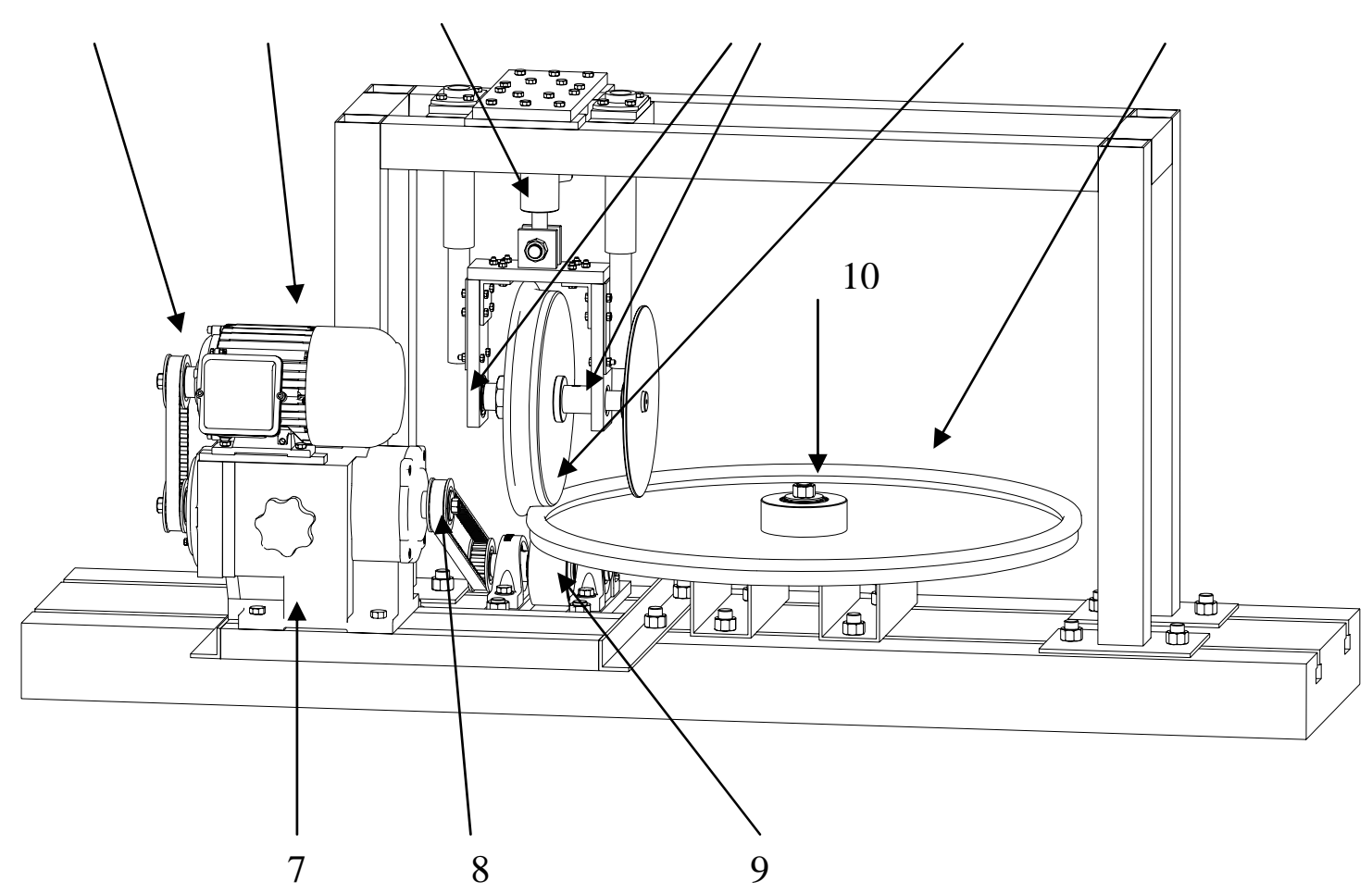

The numbers represents the following components:

1. Pulley

2. Electric motor

3. Hydraulic pack

4. Bearings in fork

5. Rail wheel

6. Track wheel

7. Gearbox

8. Pulley driving wheel

9. Driving rubber wheel

10. Track wheel bearing

Figure 1 Schematic of experimental test-rig 


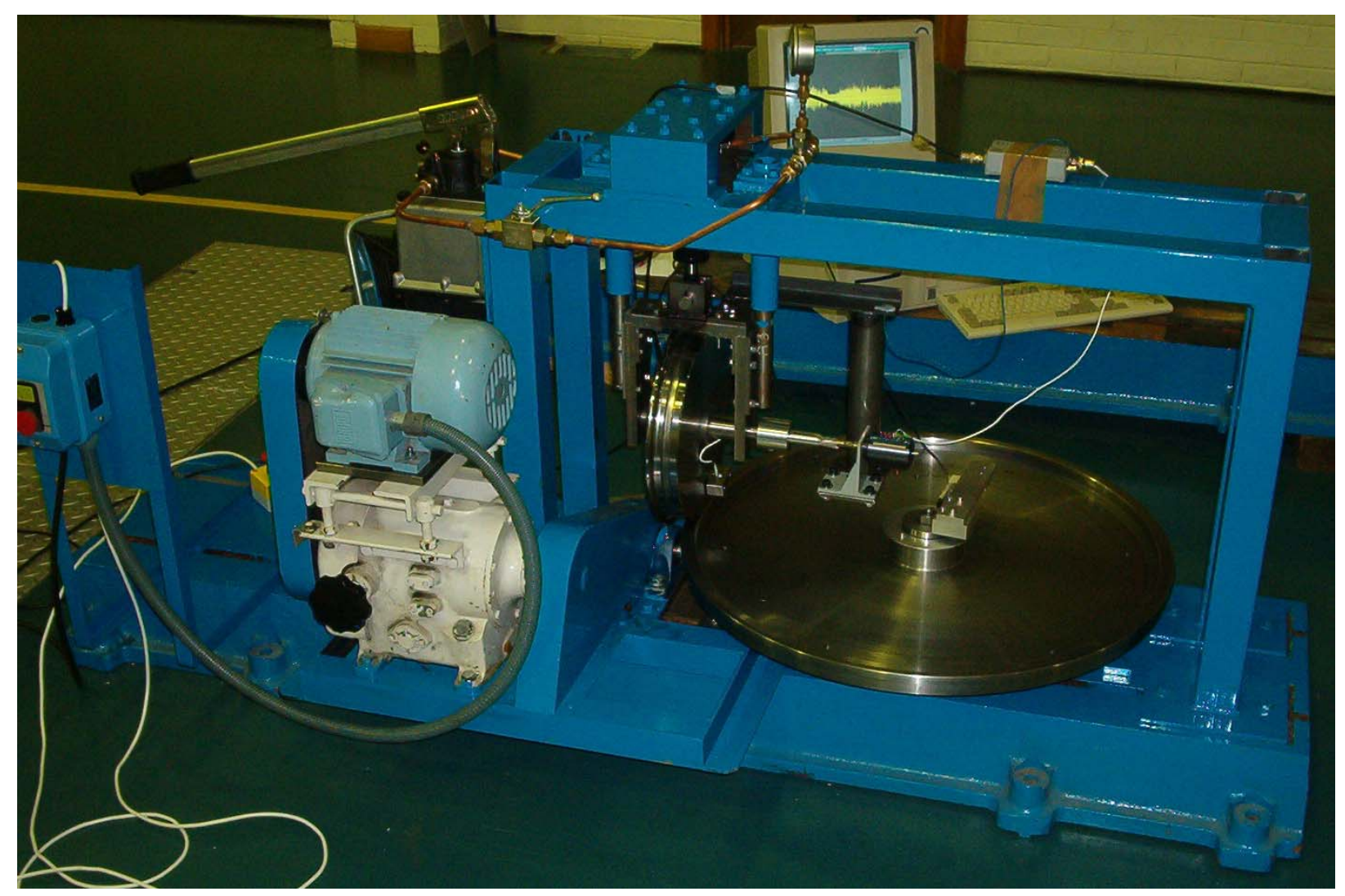

\section{Figure 2 Photograph of test-rig}

\section{DATA ACQUISITION SYSTEM}

The AE sensor used for this experiment was broadband type sensors with a relative flat response in the region between $100 \mathrm{KHz}$ to $1 \mathrm{MHz}$ (Model: WD, 'Physical Acoustics Corporation'). The sensor was placed on rail wheel and was secured with a mechanical clamp, see figure 3. The cable connecting the sensor placed on the wheel with the preamplifier was feed into the shaft and connected to a slip rig, see figure 3 . This arrangement allowed the AE sensor to be placed as close as possible to the rail wheel. A PH-12 slip rig manufactured by 'IDM Electronics Ltd' was employed. The output signal from the AE sensors was pre-amplified to $40 \mathrm{~dB}$. The pre-amplifier had a built-in bandpass filter ranging from $100 \mathrm{KHz}$ to $1,000 \mathrm{KHz}$. The signal output from the pre-amplifier 
was connected (i.e. via BNC/coaxial cable) directly to a commercial data acquisition card where a sampling rate of between $2 \mathrm{MHz}$ to $4 \mathrm{MHz}$ was used during the tests. A hand held optical tachometer was used to measure the rotational speed of the rail wheel.

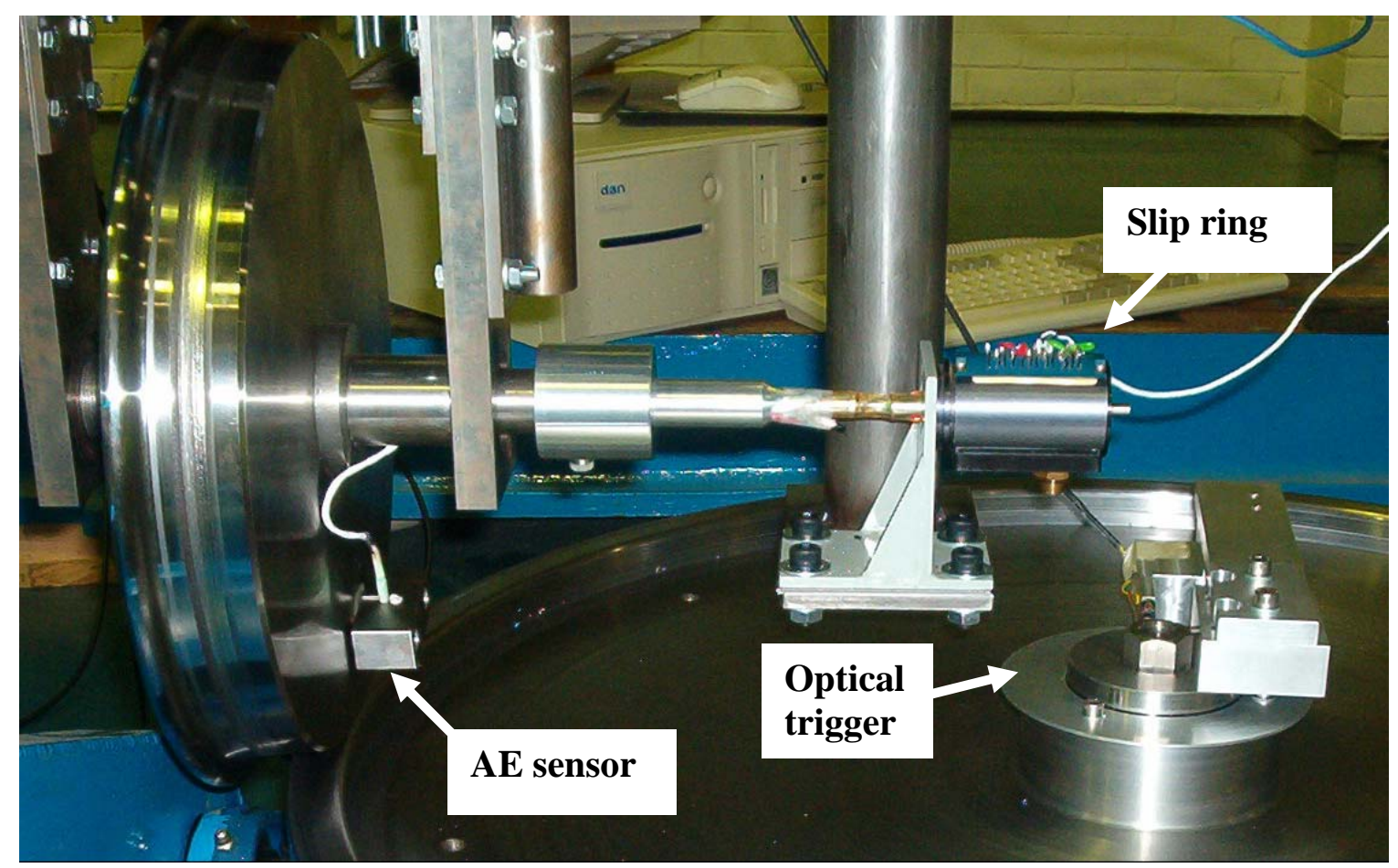

\section{Figure 3 Location of sensors on test-rig}

6 ATTENUATION TEST

Prior to undertaking any simulations it was thought prudent to ascertain if Acoustic Emissions could be transmitted across the wheel/rail interface. The test undertaken in this investigation involved pressing lead $(0.5 \mathrm{~mm} 2 \mathrm{H})$ obliquely against the surface of the wheel and rail-track until fracture. This test is widely known as the Nielson source test and was employed due to its simplicity and repeatability in generating a broadband 
AE signal [14]. It is noted that the release of strain energy within such lead breaks is caused by the sudden recoil of the compressed atoms upon the surface of the metal when the pencil snaps and does not originate within the lead itself. Between five to seven tests were undertaken at each location (load approximately 100N) and the exact location of the lead breaks is highlighted in figure 4 whilst results are presented in table 1. The results presented are relative attenuation values with reference to a lead break next to the sensor $(\mathrm{P} 1)$.

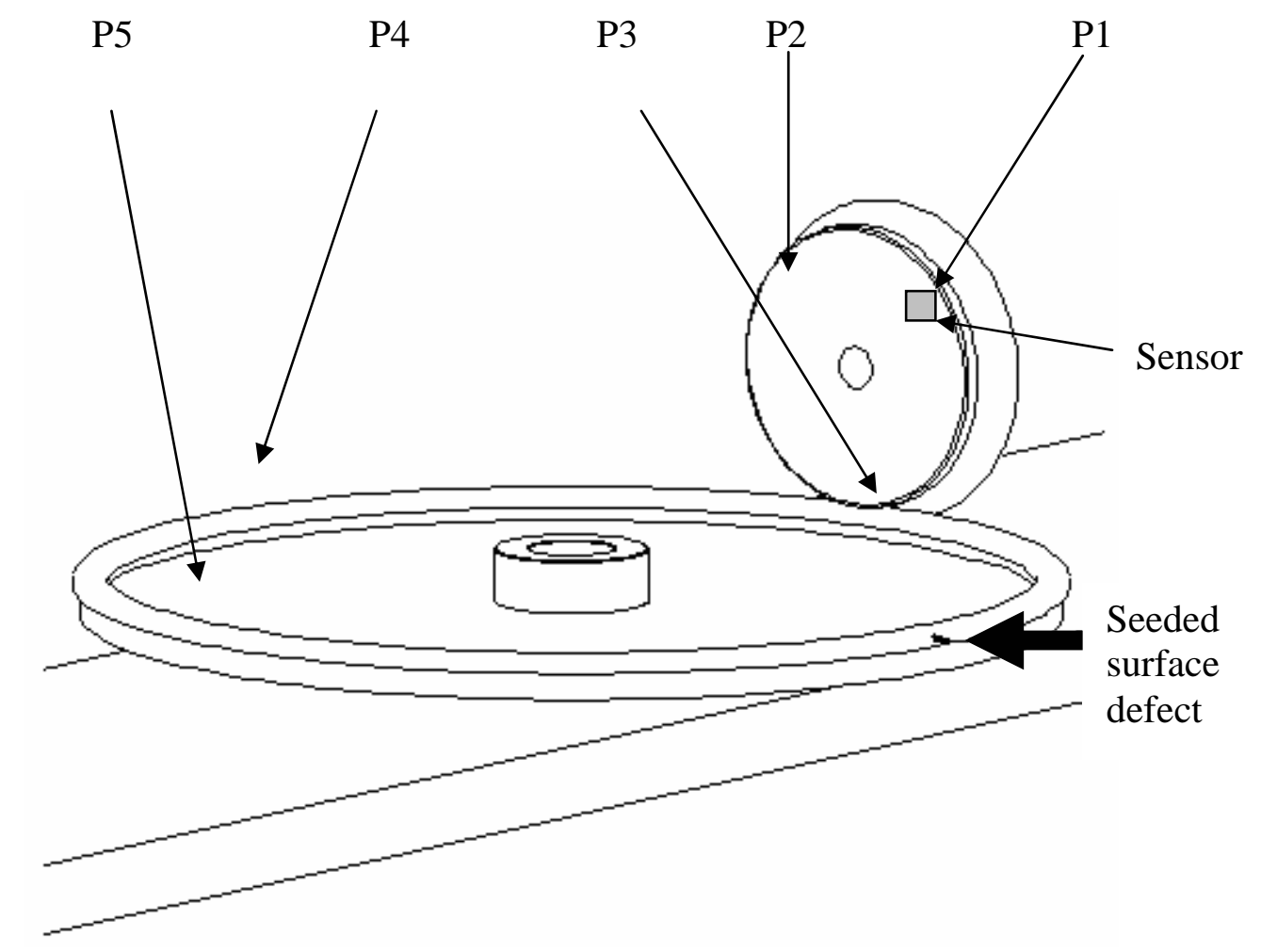

Figure $4 \quad$ Location of attenuation tests ( $P$ - position) 


\begin{tabular}{|l|c|c|c|c|c|} 
Attenuation / Position & $\mathbf{P 1}$ & $\mathbf{P 2}$ & $\mathbf{P 3}$ & $\mathbf{P 4}$ & $\mathbf{P 5}$ \\
\hline Max. Amplitude (dB) & $\mathbf{0 . 0}$ & -3.7 & -32.7 & -31.2 & -31.6 \\
Energy (dB) & $\mathbf{0 . 0}$ & 1.5 & -18.6 & -15.1 & -16.7
\end{tabular}

Table 1

\section{Results of attenuation tests}

Average attenuation values of $32 \mathrm{~dB}$ and $17 \mathrm{~dB}$ across the interface were observed in terms of maximum amplitude and energy respectively. This was a clear indication of the transmissibility of the AE generated on the track across the rail/wheel interface.

\section{TEST PROCEDURE}

The rig was run-in for approximately three hours before the actual experiments were carried out. This was undertaken at a rail wheel speed of approximately $50 \mathrm{rpm}$ and a corresponding load of $300 \mathrm{~N}$. The primary purpose of running-in was to smooth out the surface finish of the wheel and track.

The test simulations started with no-defect condition to obtain background noise conditions. Tests were undertaken at three rotational speeds; 50, 100 and 200rpm, corresponding to 2, 5, and $10 \mathrm{Km} / \mathrm{hr}$ respectively. Furthermore, four load conditions were simulated; 0, 300, 900 and 1800 N. Following the background noise tests a simulated fault condition of a surface defect was introduced to the rail track, see figures 4 and 5. This was accomplished with an engraving machine. To ensure that AE signatures were directly associated with the passage of the rail wheel over the defective 
rail track an optical trigger was employed, see figure 3. Identical speed and load conditions were undertaken as with the defect free condition. The seeded surface defect was located on the edge of the track wheel, where the rail wheel was in contact with the track wheel. The edge of the track wheel is similar to the gauge corner of a rail track. The length of the surface defect was approximately $5 \mathrm{~mm}$, the depth approximately 1 $\mathrm{mm}$ and the width approximately $2 \mathrm{~mm}$, see figure 5 .

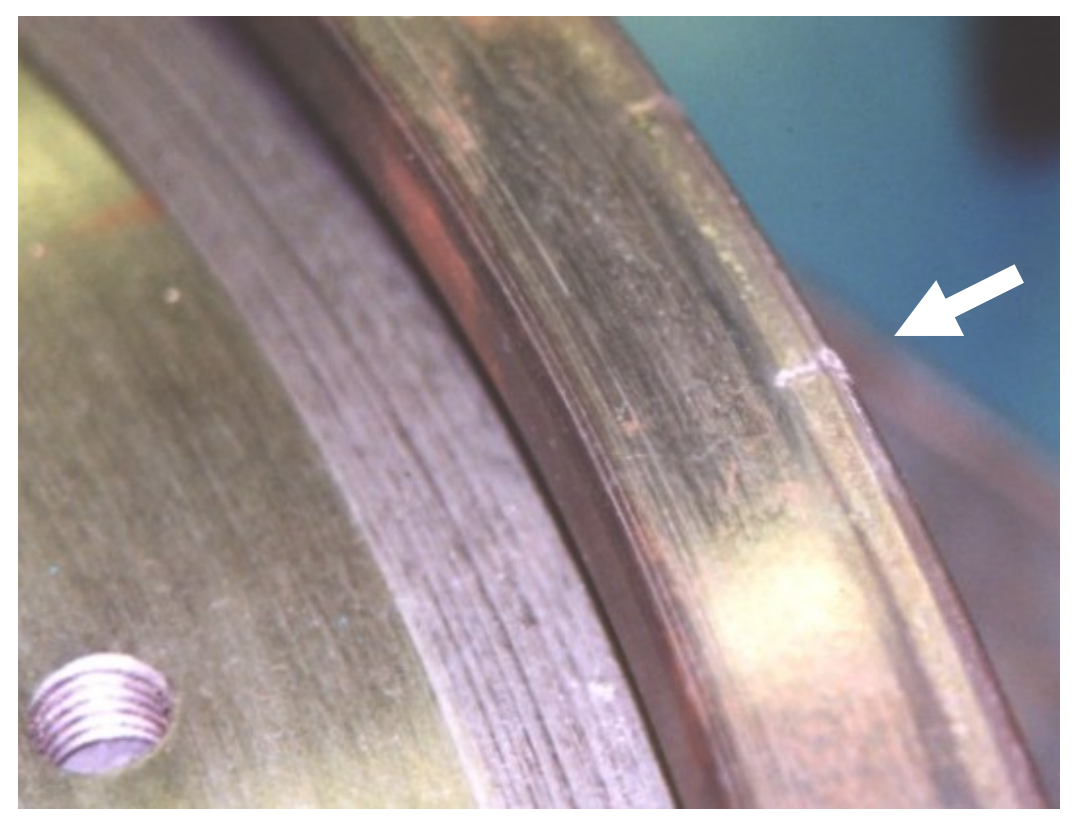

\section{Figure 5 Photograph of seeded defect}

An artificial defect of this type is known to produce AE activity and is considered to be representative of a surface discontinuity, such as a surface crack. It was not intended to initiate crack propagation from the seeded defect but rather assess the applicability of AE from a position of assumed maturity of a surface crack/discontinuity. Whilst it could be argued that this is not entirely representative, the reader is reminded that at this stage this is a fundamental study. 


\section{DEFECT SIMULATIONS AND OPERATIONAL NOISE}

Acoustic Emission signatures associated with five different speeds at $0 \mathrm{~N}$ is shown in figure 6. Due to the limitations detailed earlier speeds of 350rpm and 450rpm (19 and $25 \mathrm{Km} / \mathrm{hr}$ ) were not investigated at higher loads. It must be noted that the $0 \mathrm{~N}$ load specification was not literally 'zero' as some preload (approximately 10N) was required to maintain frictional contact. Clearly AE activity increased (observe the different scales on the y-axis of figure 6) with increasing speed at this load condition. At speeds of 50 and 100rpm, no AE activity was noted. The AE signatures associated with these conditions and displayed in figure 6 are signatures of system electronic noise only. These observations of increased AE activity with speed for a load condition reinforce the findings of Sarychev [12].

Typical AE signatures from defect and defect free conditions are shown in figures 7 and 8. In all cases four load conditions are presented with $0 \mathrm{~N}$ at the top of each figure and $1800 \mathrm{~N}$ at the bottom. Three speed conditions were investigated, 50, 100 and $200 \mathrm{rpm}$. 

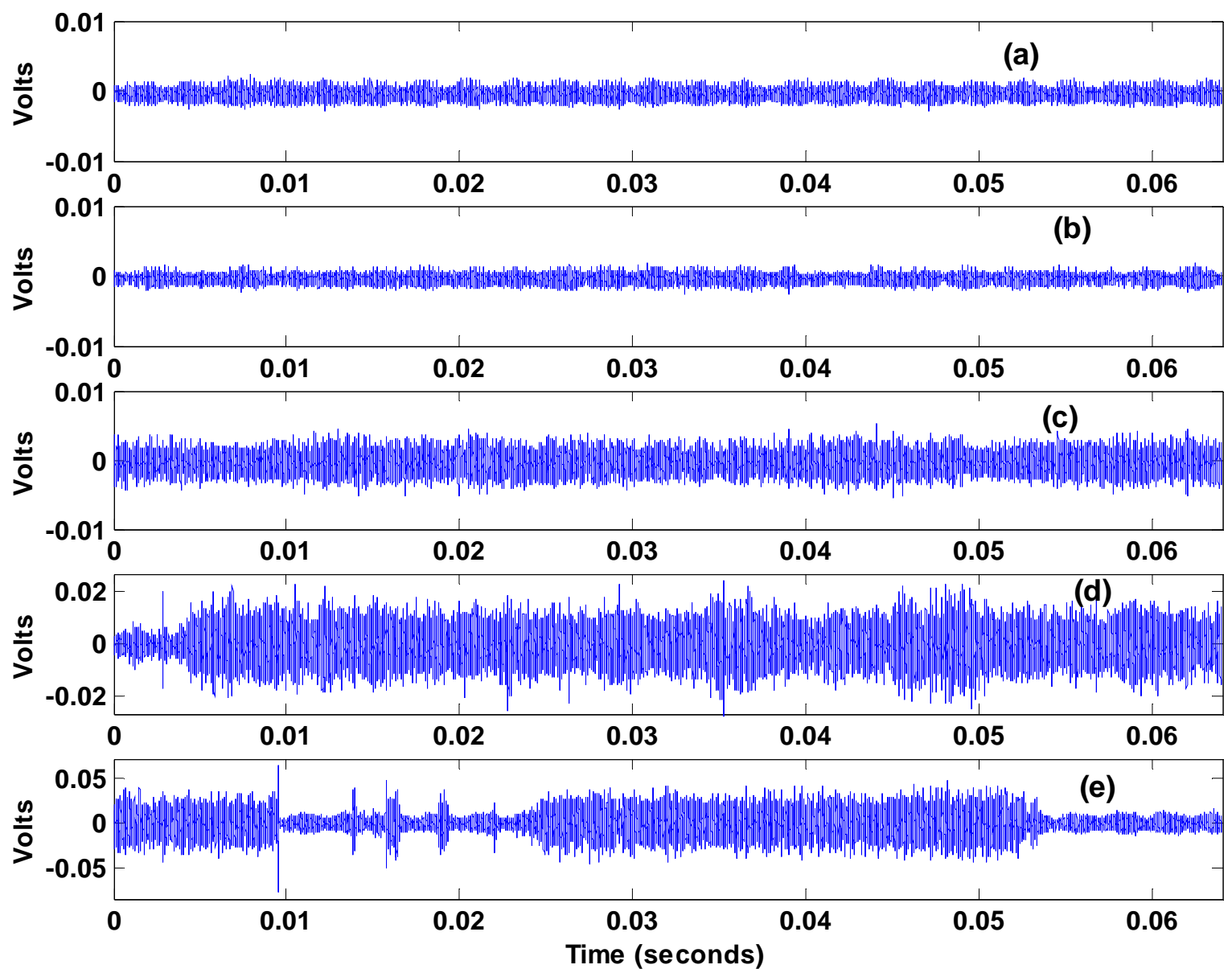

Figure 6 Background AE activity for five speeds under no load condition

(a) 50rpm (b) 100rpm (c) 200rpm (d) 350 rpm (e) 460 rpm 

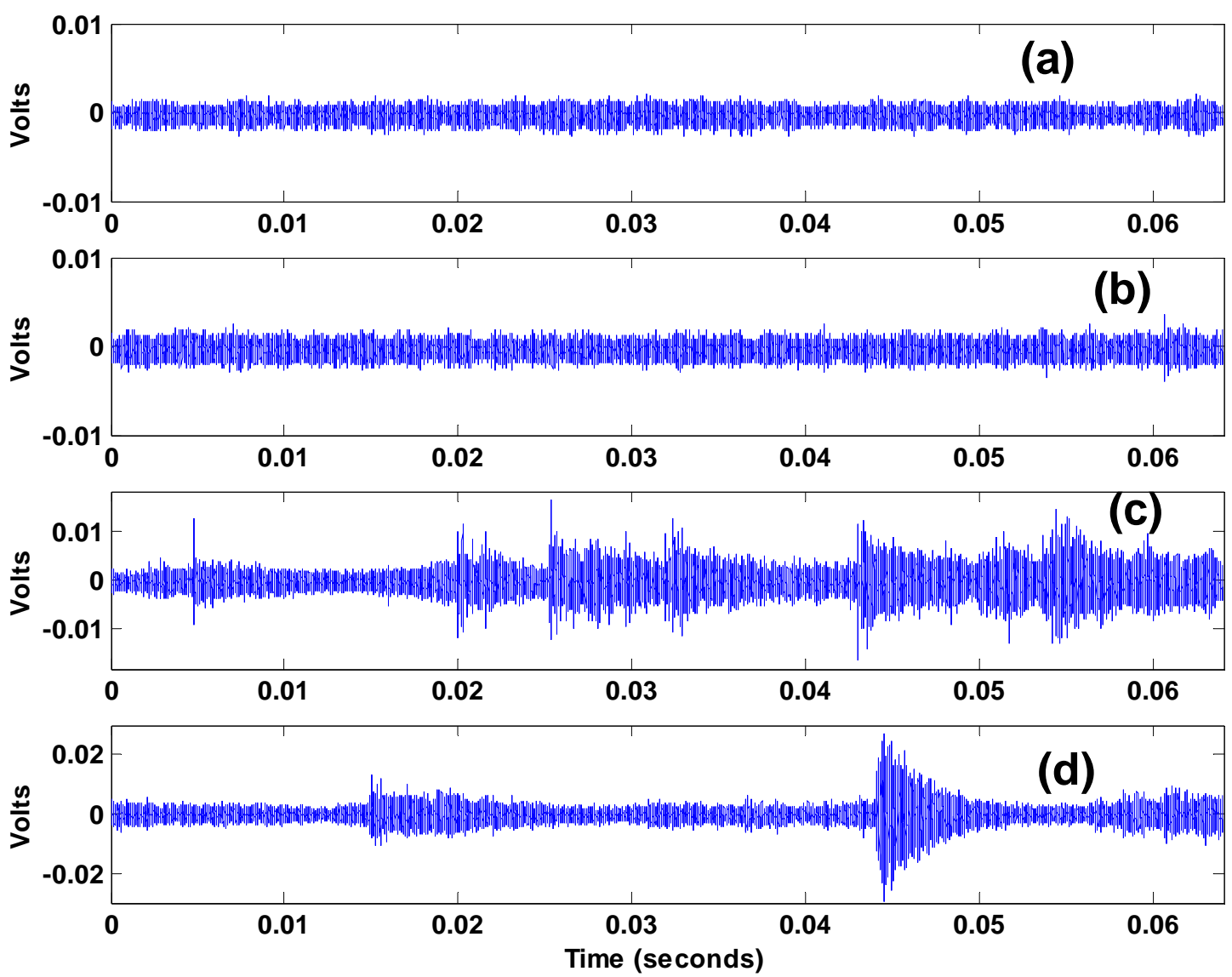

Figure 7 Background AE activity for four load conditions; no seeded defect Speed: $100 \mathrm{rpm}(6 \mathrm{Km} / \mathrm{hr})$; Load (a) $0 \mathrm{~N}$ (b) $300 \mathrm{~N}$ (c) $900 \mathrm{~N}$ (d) $1800 \mathrm{~N}$ 

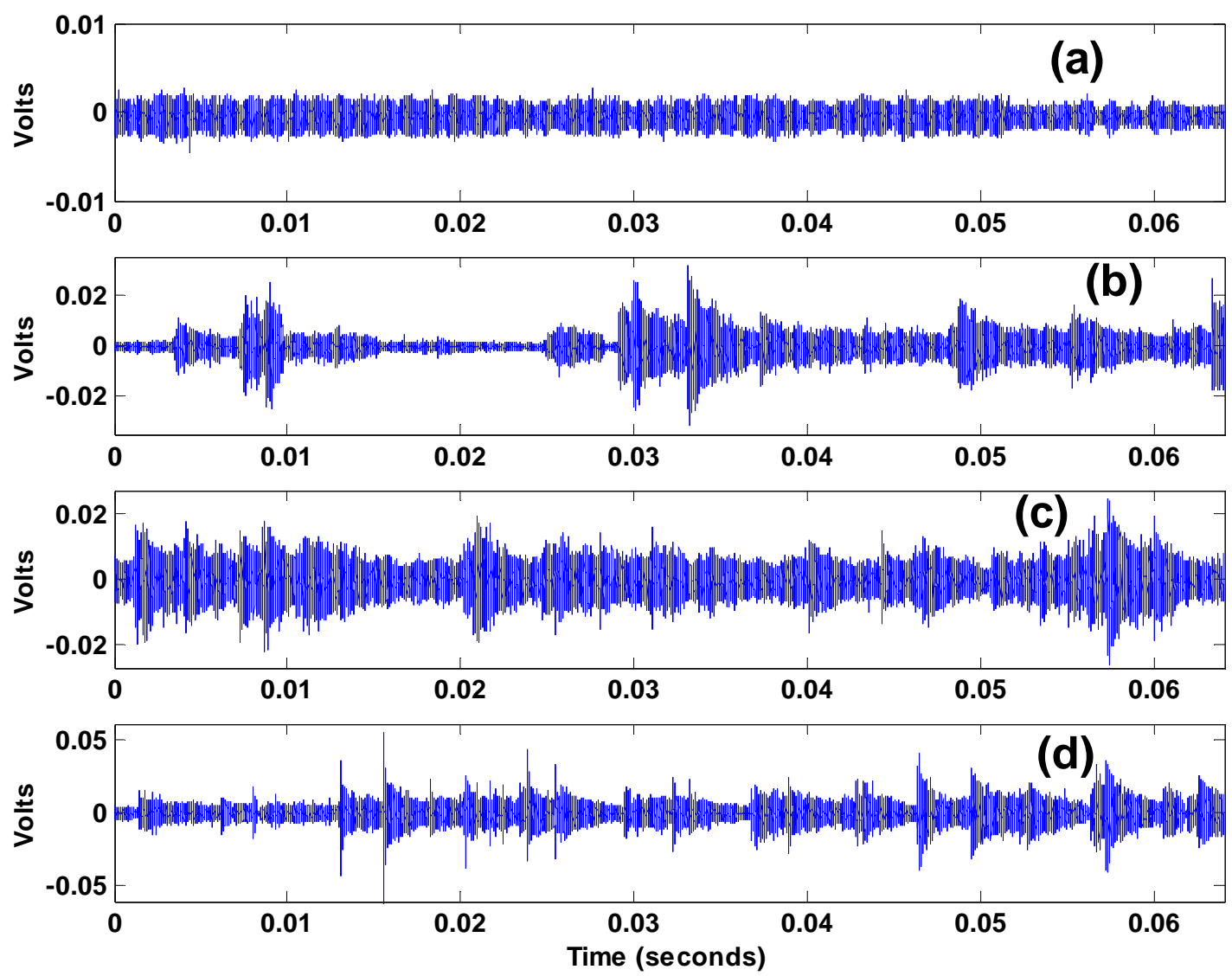

Figure 8 Defect AE activity for four load conditions with seeded defect

Speed: $100 \mathrm{rpm}(6 \mathrm{Km} / \mathrm{hr})$; Load (a) $0 \mathrm{~N}$ (b) $300 \mathrm{~N}$ (c) $900 \mathrm{~N}$ (d) $1800 \mathrm{~N}$

It was hoped that the seeded surface discontinuity would result in AE activity, however, the natural wear process of the test specimen could not be controlled. This was primarily due to the fact that the surfaces of the wheel and rail had not been hardened. A consequence of this was the inability to differentiate between $\mathrm{AE}$ generated from the seeded defect to that from natural wear. The AE signatures presented in figure 8 cover a time window of 0 to 0.064 seconds that includes the rail wheel passing over the defect on the track. Irrespective of this, observations of progressive wear on the rail track/wheel interface were associated with increasing AE transient bursts. This 
observation was noted during simulations. At the start of the test, the surface of the rail/track interface did not how any visible signs of wear. However, as the test simulations progressed, signs of wear on the interface became apparent, as did the rate of AE burst activity, see figures 11 and 12 .

A frequency spectrum of a typical AE transient burst at the start of the tests is highlighted in figure 9 whilst a spectrum of an AE burst signature for the same test condition recorded a few hours later is displayed in figure 10.
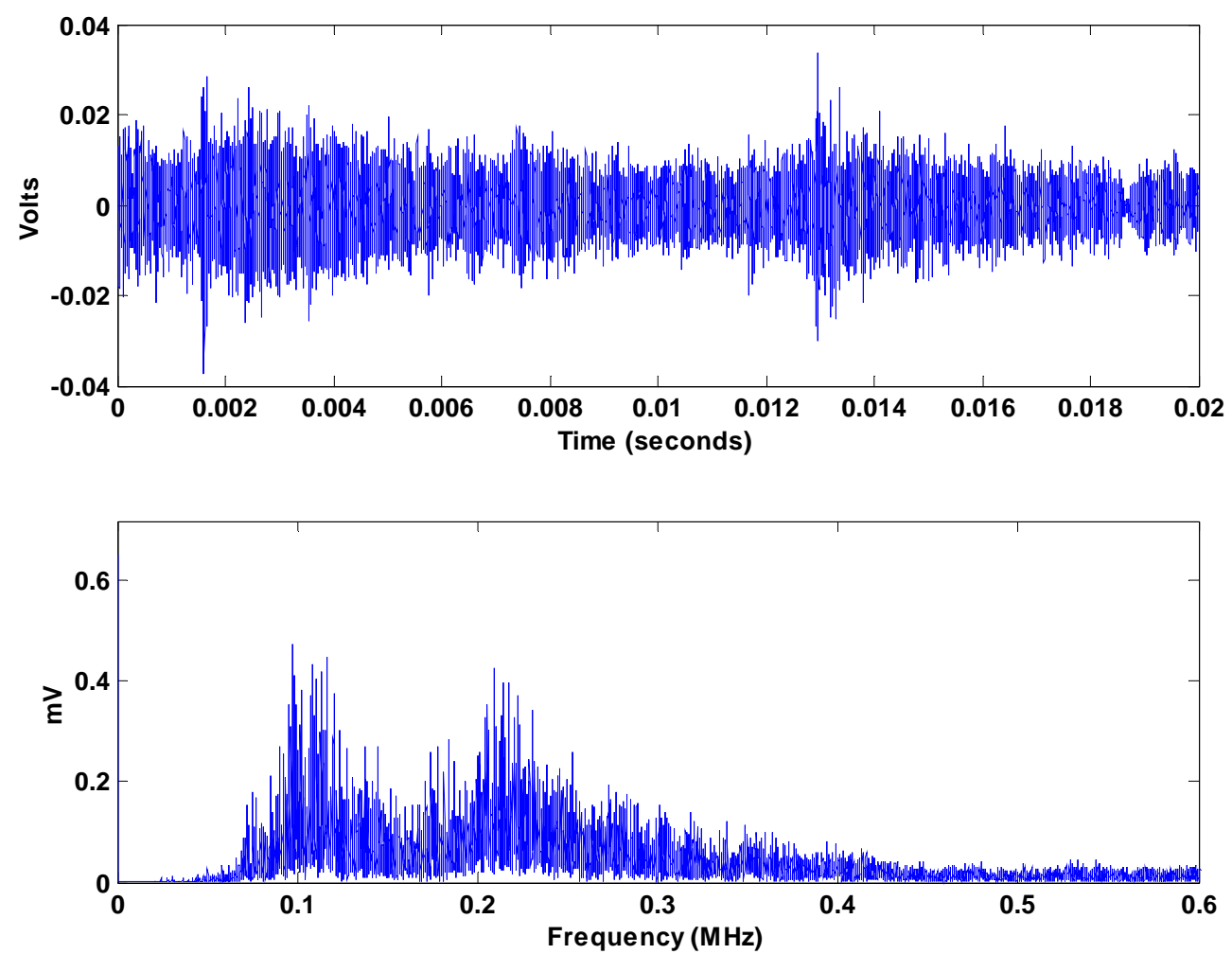

Figure 9 Frequency spectrum of AE signature associated with background noise; speed 200rpm, load 1800N 

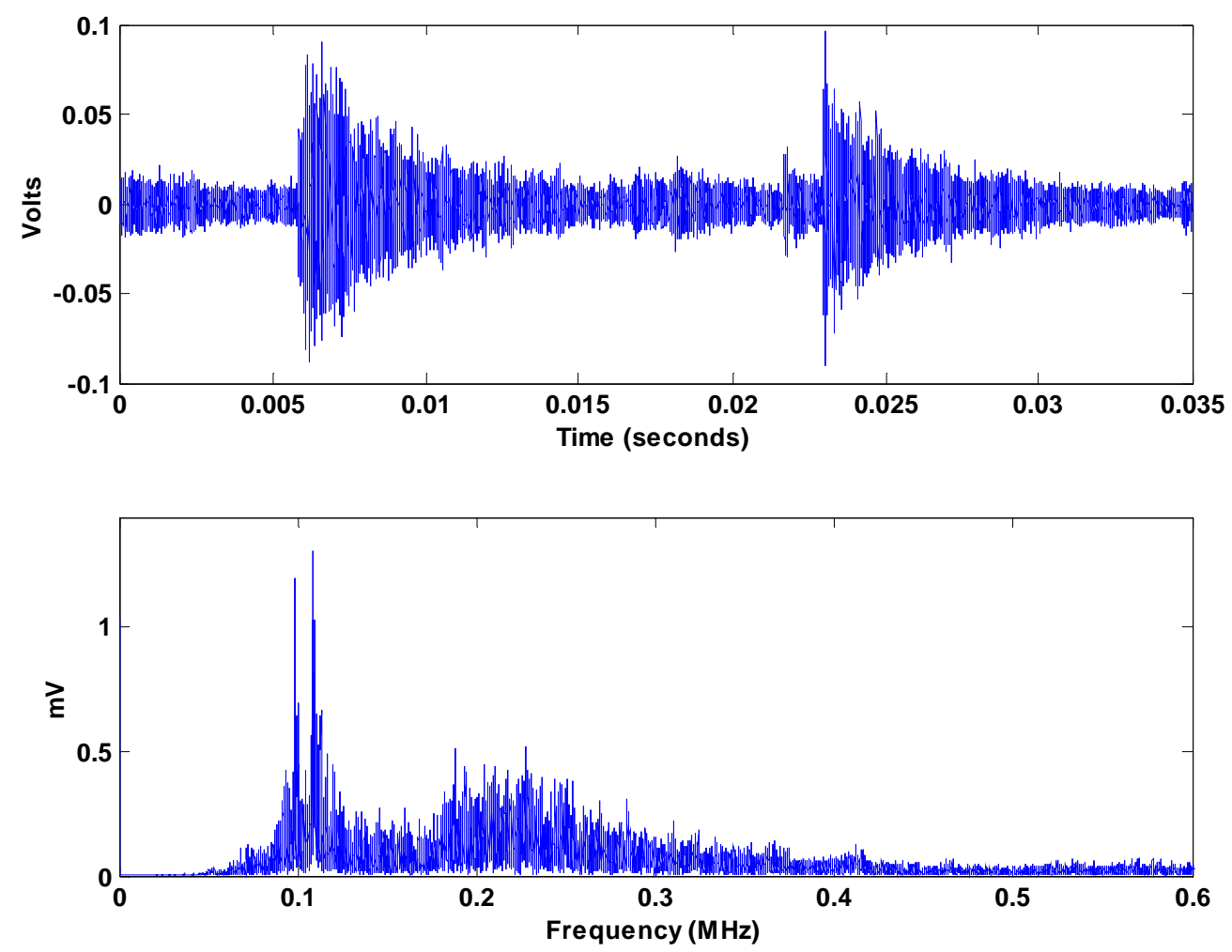

Figure 10 Frequency spectrum of AE burst associated with increased wear on the rail track; speed 200rpm, load 1800N

\section{DISCUSSIONS}

From the simulated conditions it was observed that AE transient burst activity increased with progressive wear, however, the author's attempts to relate the rate of this activity with load and speed could not be ascertained. Whilst early observations showed AE burst activity and underlying levels to increase with speed, this phenomenon did not hold true as the wear progressed. This unpredictable relationship was noted by Lingard et al [13] where a correlation between wear and AE activity for varying speeds and loads was not discernible. Associating specific AE transient burst to the simulated 
defect was not possible for the reasons already detailed. It must be noted that the investigation centered on mild steel which is not typical of the rail head, as such the direct relevance of these results to actual operational conditions can only be postulated at present.

From the results it was observed that AE activity under background noise conditions was only detectable when the load was above $900 \mathrm{~N}$ for all speeds. These observations were made at the start of the experiment. However, after the defect was seeded AE activity was detectable at loads above $300 \mathrm{~N}$ for all speed conditions. More importantly, the rate of AE activity as the rail wheel passed the defective rail track was significantly greater than the defect free condition, see figure 7 and 8 . This was clearly due to the progressive wear of the contact region and not due to the presence of the defect, see figures 11 and 12. It is interesting to note that the frequency content of AE bursts at the start of the tests and a few hours later were identical, see figures 9 and 10 . This is not surprising and confirms the view that the AE transients were generated from the same mechanism, frictional contact. 
NDT and E International, 37 (7), pp. 507-516, 2004

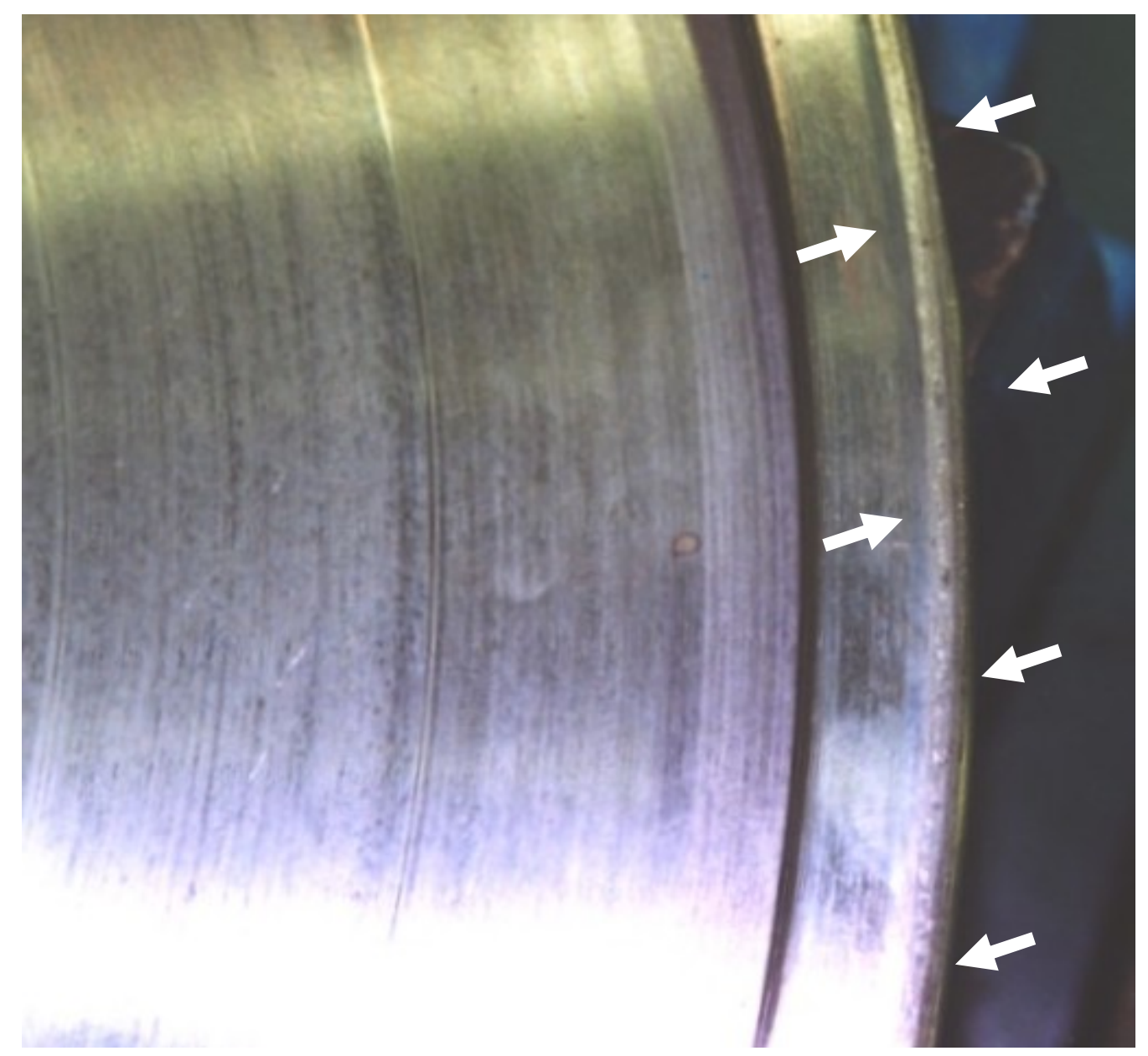

Figure 11 Evidence of wear on the circumferential periphery of rail track wheel 


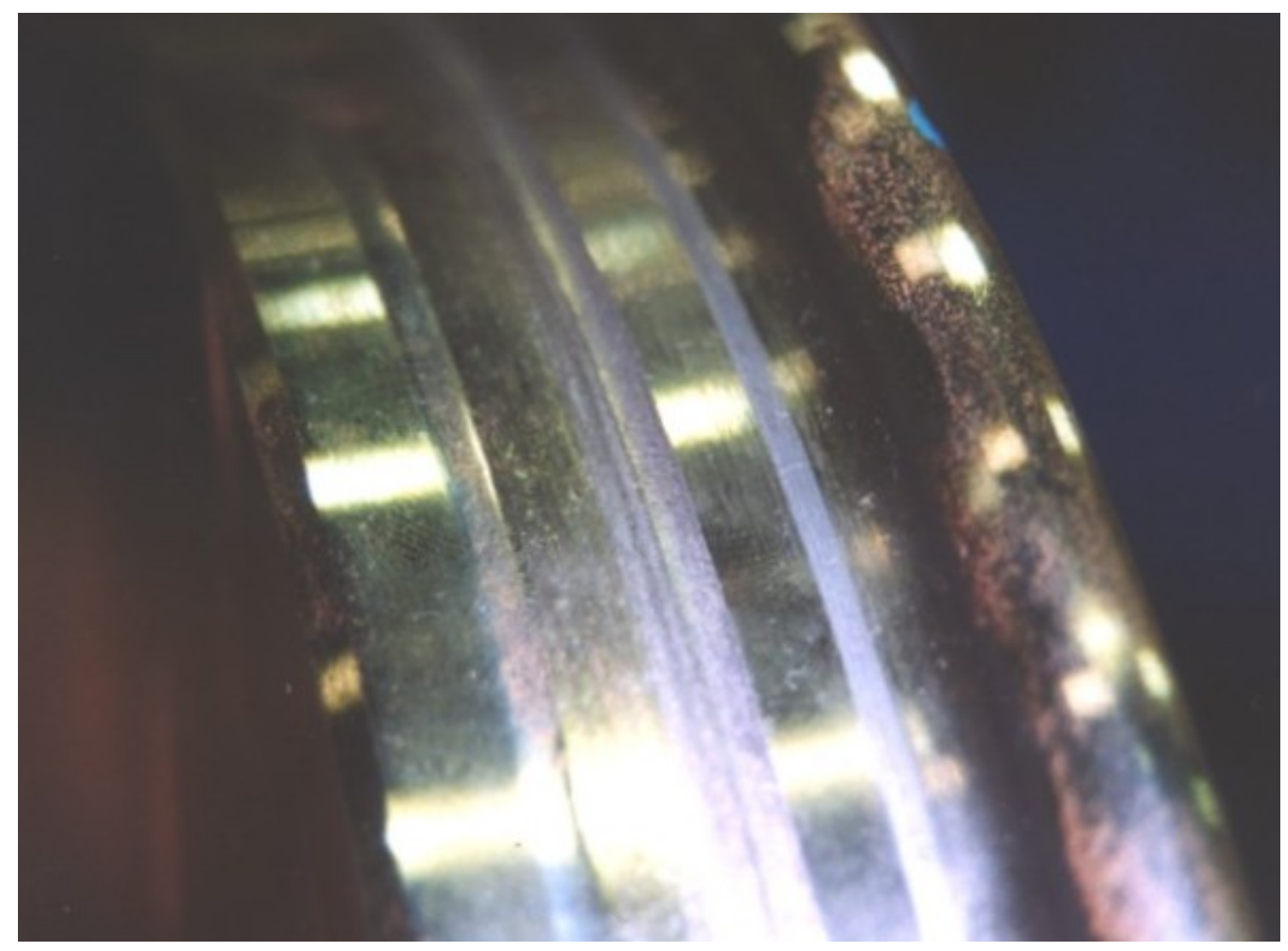

\section{Figure 12 Evidence of wear on the rail wheel}

Whilst the initial objective of identifying a surface defect was not successfully accomplished observations of AE activity with progressive wear from the rail wheel/track interface have been encouraging. The test-rig design and transmission break-up of the AE signature see figures 14 and 15, limited the test conditions which could have been carried out. This breakage was noted at speeds above 200rpm and loads of $300 \mathrm{~N}$. As a direct result of this draw back a new means of transferring AE data from a rotating sensor are been investigated with a prototype under design. 
NDT and E International, 37 (7), pp. 507-516, 2004

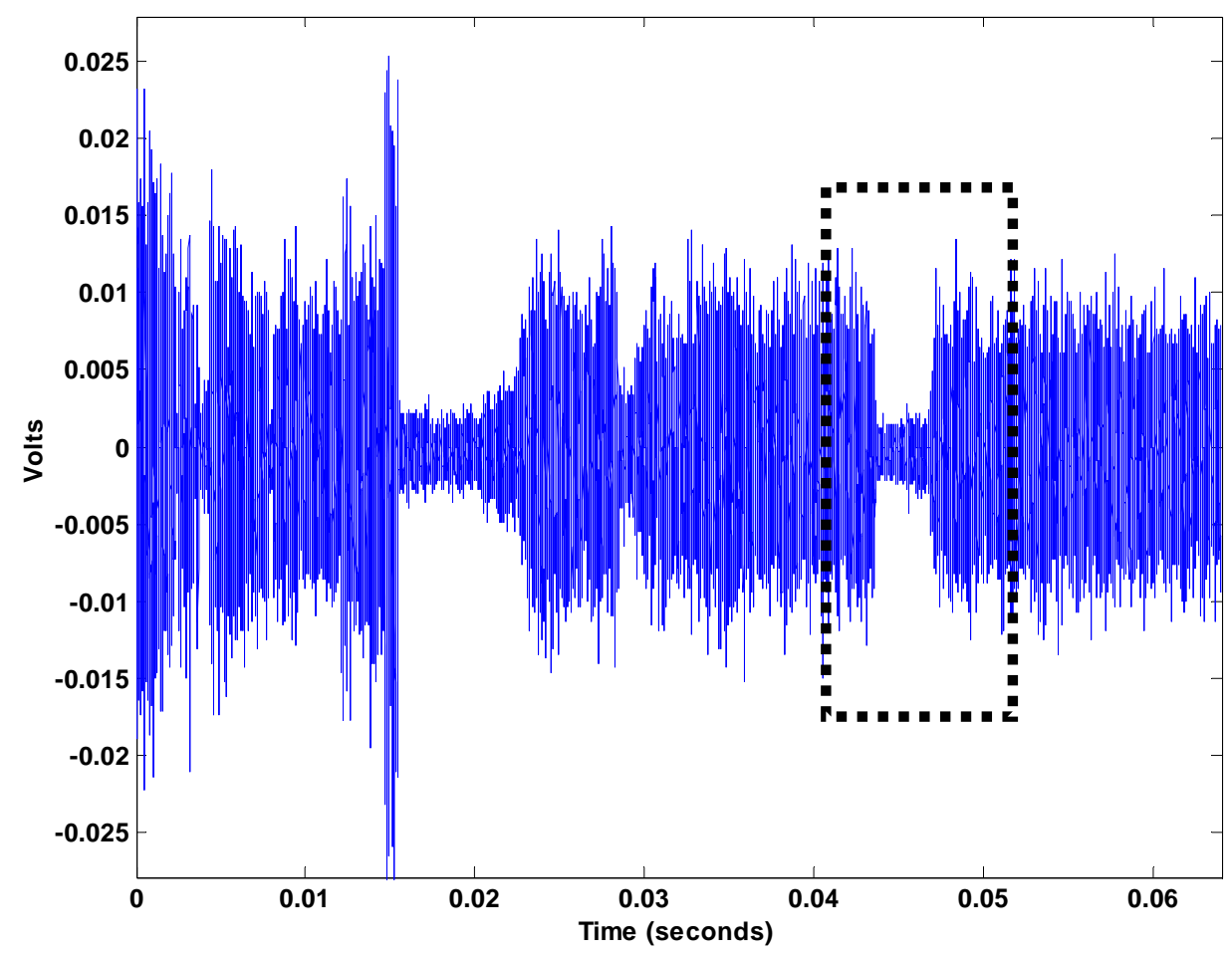

Figure 13 Break-up of AE signature

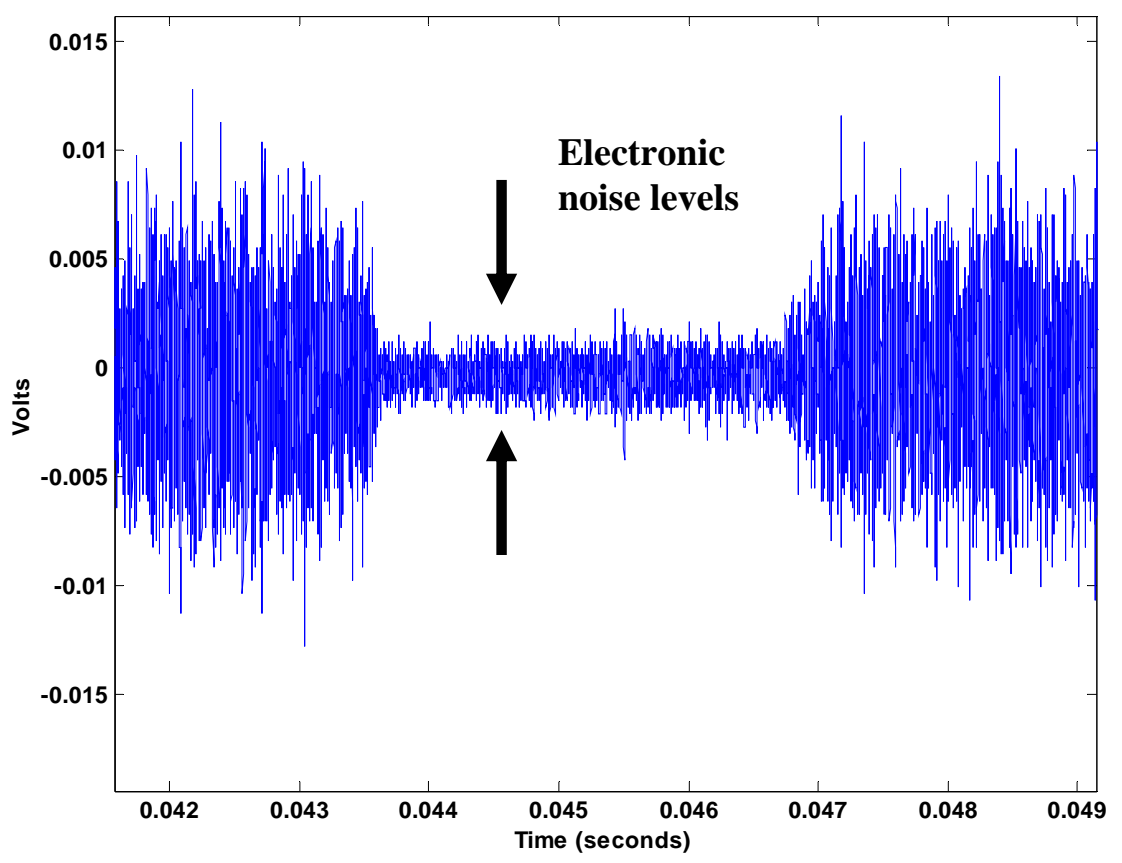

Figure 14 Zoom of figure 13 


\section{Conclusion}

It has been shown that the AE sensor, positioned on the side of the rail wheel, was able to pick up $\mathrm{AE}$ activity from the rail track. The $\mathrm{AE}$ activity was attributed to the progressive wear of the rail wheel/track frictional process. As wear progressed the rate of AE burst activity increased. This paper has demonstrated the potential of applying AE to rail track defect detection. The research programme reported is in its infancy but the results to date are encouraging.

\section{REFERENCES}

1. Nilsson, R. and Olofsson, U., Surface cracks and wear of rail; a full-scale test on a commuter train track. Institute of Mechanical Engineers. Vol. 216 Part F, 249-264, 2001.

2. Rolling Contact Fatigue in Rails; A Guide to Current Understanding and Practice. Produced by RAILTRACK PLC. RT/PWG/001. February 2001. Issue 1. Heron Press, Kings Norton, Birmingham.

3. R. Krull, H. Hintze, M. Luke, M. Thomas, R. Pohl, S. Rühe. Eddy current Detection of Head Checks on the Gauge Corners of Rails: Recent Results. NDT net, June 2002, Vol. 7, No.06.

4. Toutountzakis, T. and Mba, D. (2003). Observation of Acoustic Emission Activity During Gear Defect Diagnosis. NDT and E International. 36(7), pp 471-477. 
5. Mba, D. and Bannister, R.H. (1999). Condition monitoring of low-speed rotating machinery using stress waves: Part1 and Part 2. Proc Inst Mech Engrs. Vol 213, Part E, pp 153-185.

6. Holroyd, T. and Randall, N. (1992). The Use of Acoustic Emission for Machine Condition Monitoring. British Journal of Non-Destructive Testing. Vol. 35(2), pp 75.

7. Mba, D. (2002). Applicability of acoustic emissions to monitoring the mechanical integrity of bolted structures in low speed rotating machinery: case study. NDT and E International. Vol 35, No. 5, pp. 293-300.

8. Mba, D., Cooke, A., Roby, D. and Hewitt, G. (2003). Opportunities offered by acoustic emission for shaft-seal rubbing in power generation turbines; a case study sponsored by the British Institute of NDT. International Conference on Condition Monitoring. Oxford, UK, 2-4 July 2003, 280-286, ISBN 1901892174.

9. Morhain, A, Mba, D, Bearing defect diagnosis and acoustic emission Journal of Engineering Tribology, I Mech E, Vol 217, No. 4, Part J, p 257-272, 2003. ISSN $1350-6501$

10. Green, A. P. Friction between un-lubricated metals: a theoretical analysis of the junction model. In Proc. Of the Royal Society of London 1955; Vol 228(A): 191204.

11. M.N. Bassim, S. ST. Lawrence and C.D. Liu. Detection of the onset of fatigue crack growth in rail steels using acoustic emission. Engineering Fracture Mechanics. Vol. 47, no. 2, pp 207-214, 1994.

12. Sarychev, G. A. and Shchavelin, V. M., Acoustic emission method for research and control of friction pairs. Tribology International, 1991, Vol 24, Issue 1, 11-16. 
NDT and E International, 37 (7), pp. 507-516, 2004

13. Liangand, S. Dornfield, D. (1987), "Punch stretching Process Monitoring using Acoustic Emission Signal Analysis-Part-1/2”, Journal of Acoustic Emission, vol. 6(1), pp 29.

14. ASTM E 976-96 